\title{
KLUTUK BANANA (MUSA BALBISIANA COLLA) PEEL FRACTIONS: ANTIOXIDANT AND ANTIHYPERGLYCEMIC POTENTIAL
}

\section{TITA NOFIANTI ${ }^{1,3^{*}}$, AHMAD MUHTADI ${ }^{1}$, IRDA FIDRIANNY ${ }^{2}$, AI SAMROTUL FUADAH ${ }^{3}$, VERA NURVIANA ${ }^{3}$, RUSWANTO $^{3}$}

1Department of Pharmacology, Faculty of Pharmacy, Padjadjaran University, Bandung, Indonesia, ${ }^{2}$ Department of Pharmaceutical Biology, School of Pharmacy, Bandung Institute of Technology, Indonesia, ${ }^{3}$ Department of Pharmacology, Institute of Health Science of Bakti Tunas Husada Tasikmalaya, West Java, Indonesia *Email: titanofianti.wamsu@gmail.com

Received: 02 Sep 2020, Revised and Accepted: 07 Oct 2020

\section{ABSTRACT}

Objective: The purposes of this research were the antihyperglycemic and antioxidant determination of klutuk banana peel fractions through the oral glucose tolerance test (OGTT) and DPPH (2,2-diphenyl-1-picrylhydrazyl) methods, respectively.

Methods: Klutuk banana peel was extracted by reflux method and followed by fractionation using n-hexane and ethyl acetate solvents by liquidliquid extraction method. The statistical analysis used by one-way ANOVA and post hoc Tukey.

Results: The results of OGTT showed that ethyl acetate fraction of klutuk banana peel $14.5 \mathrm{mg} / \mathrm{kg}$ bw demonstrated higher activity to decrease blood glucose level compared to the other groups as much-32\%,-49\%,-47\% and-40\% at min 30, 60, 90 and 120 , respectively. The IC 50 of ethyl acetate fraction of klutuk banana peel was $0.3708 \mu \mathrm{g} / \mathrm{ml}$, and its antioxidant activity index (AAI) 40.45 .

Conclusion: The ethyl acetate fraction of klutuk peel presented very strong antioxidant and antihyperglycemic activity.

Keywords: Antihyperglycemic, Antioxidant, Musa balbisiana Colla, Klutuk banana peel

(C) 2021 The Authors. Published by Innovare Academic Sciences Pvt Ltd. This is an open access article under the CC BY license(http://creativecommons.org/licenses/by/4.0/) DOI: http://dx.doi.org/10.22159/ijap.2021.v13s2.01 Journal homepage: https://innovareacademics.in/journals/index.php/ijap

\section{INTRODUCTION}

The most prevalent endocrine condition arising from a defect in insulin secretion, insulin tolerance or a mixture of these is diabetes mellitus (DM) [1]. DM is the third most important source of morbidity and mortality [2]. Consumption of antioxidant rich food able to improve immunity and reduce the disease risk factor, such as diabetes $[3,4]$. Banana is considered one of the most essential foods abundant in antioxidants [5]. Banana is widely eaten by many individuals and the composition of bioactive compounds has important antioxidant activities that have been beneficial in holding the body against different oxidative stress [6]. Banana peel, normally discarded, is also a decent source of dietary fiber and bioactive compounds [7]. Many experiments have recorded high levels of essential bioactive compounds in banana peel than pulp that could be used as a functional source of food against many chronic diseases like diabetes mellitus [5, 8-10]. Further research was needed to discover and apply dietary fiber and natural antioxidants that contained in banana peel for health benefits. Therefore, we conducted the antioxidant and antihyperglycemic activity of the fractions of n-hexane, ethyl acetate and water extracts from the peel of klutuk banana (Musa balbisiana Colla).

\section{MATERIALS AND METHODS}

\section{Material collection and preparation}

The peels of klutuk banana ( $M$. balbisiana Colla) was obtained on November 2018 from Tasikmalaya, West Java, Indonesia. The plant was identified by Faculty of Mathematics and Natural Sciences; Department of Biology, Padjadjaran University, with no. 156/HB/11/2018.

\section{Preparation of crude drug, extract and fraction}

Peels of klutuk banana was washed, dried, cut into pieces, followed by grinding. The powder was stored at a dry place for further use. Peels of klutuk banana ( $M$. balbisiana Colla) was extracted by reflux method using $96 \%$ ethanol for $3 \mathrm{~h}$ and repeated three times. Furthermore, the sample was filtered through filter paper and then vaporated by the rotary evaporator. This extract was kept in the refrigerator at $4{ }^{\circ} \mathrm{C}$ for further use. The ethanolic extract was added by hot water and fractionated by liquid-liquid extraction method using ethyl acetate and n-hexane solvents, then produced ethyl acetate, n-hexane, and water fractions.

\section{Determination of extract and fraction density}

The extract temperature was adjusted to approximately $20^{\circ} \mathrm{C}$, put the $1 \%$ extract into an empty pycnometer and remove an excess of the extract. Furthermore, adjusted the temperature of the pycnometer to $25{ }^{\circ} \mathrm{C}$ then weighed. Calculated the difference between the empty pycnometer weight from the filled pycnometer weight. The density of the $1 \%$ extract result was obtained by dividing the weight of the extract with the volume of pycnometer [11].

\section{Phytochemical screening}

The phytochemical screening was done to detect the secondary metabolites such as alkaloid, flavonoid, saponin, steroid/triterpenoid, tannin, quinone, and phenols. Phytochemical screening was completed on crude drug, extract and fractions of klutuk banana (M. balbisiana Colla) [12].

\section{Antioxidant activity}

The activity of antioxidant was carried out for ethyl acetate, n-hexane, and water fractions of klutuk banana (Musa balbisiana Colla) by calculating scavenging effect of the free radical of DPPH. The diluted test solutions of peel extracts were equipped in methanol. The DPPH 30 $\mu \mathrm{g} / \mathrm{ml}$ was prepared in methanol and $1 \mathrm{ml}$ of this solution was diverse with $1 \mathrm{ml}$ of sample solutions. These mixtures were saved in the dark room for $30 \mathrm{~min}$. The absorbance value was measured at $\lambda 516 \mathrm{~nm}$ by a UV-Visible spectrophotometer. The DPPH solution was utilized as control [13]. The absorbance was recorded and \% inhibition was calculated. The $\mathrm{IC}_{50}$ value was determined through utilizing calibration curve, in a while the Antioxidant Activity Index (AAI) was determined by dividing final concentration of DPPH with $\mathrm{IC}_{50}$ value.

Experimental animals

Mice (22-25 g) were obtained from the Experimental Animal Application and Research Center of Biofarma. Under normal 
laboratory conditions of $22 \pm 3{ }^{\circ} \mathrm{C}$ temperature and relative humidity $70 \%$ and $12 \mathrm{~h}$ light and dark cycle preserved, free access to regular pellet diet and water ad Librium, animals of either sex were stored. An experimental protocol was accepted by the Institutional Animal Ethics Committee (330/UN6. KeP/EC/2019).

\section{Antihyperglycemic activity}

There were 13 groups and each group contained 3 animals. Negative control (CMC-Na 0.5\%); positive control (metformin $65 \mathrm{mg} / \mathrm{kg} \mathrm{bw}$ ); FHD1 (n-hexana klutuk peel fraction $6.5 \mathrm{mg} / \mathrm{kg}$ bw), FHD2 $(13 \mathrm{mg} / \mathrm{kg}$ bw), FHD3 (14.5 mg/kg bw), FHD4 (26 mg/kg bw), FED1 (ethyl acetate klutuk peel fraction $7.25 \mathrm{mg} / \mathrm{kg} \mathrm{bw})$, FED2 (14.5 mg/kg bw), FED3 (29 $\mathrm{mg} / \mathrm{kg} \mathrm{bw}$ ), FWD1 (water klutuk peel fraction $14.5 \mathrm{mg} / \mathrm{kg}$ bw), FWD2 (16 mg/kg bw), FWD3 (32 mg/kg bw), and FWD4 (64 mg/kg bw).

The oral glucose tolerance test (OGTT) was applied to evaluate the ability of glucose metabolism regulation, glucose-induced insulin secretion, and glycemic changes. After fasting $12 \mathrm{~h}$ previously, all mice were given different treatments depending on the groups, then after $30 \mathrm{~min}$ all groups was orally directed of glucose $(2 \mathrm{~g} / \mathrm{kg} \mathrm{bw})$. The glucose concentration was determined from the collected blood tail vein from at 0 (just before glucose administration), 30, 60, 90, and 120 -min using glucose oxidase-peroxidase reactive strips and the glucometer (Gluco-Dr Biosensor AGM 2100, All Medicus Co., Ltd, Korea) [14].

\section{Statistical analysis}

All data were stated as mean \pm SD. The SPSS package (version 16) was applied in statistical analysis. The difference test between groups was performed by one-way ANOVA, be continued using post hoc Tukey. The one-way analysis of variance (ANOVA) is used to evaluate if there are any statistically significant discrepancies between the means of two or more distinct (unrelated) groups $[15,16]$.

\section{RESULTS AND DISCUSSION}

\section{Determination of extract and fraction density}

Plant determination was carried out to find out the truth of the identity of the banana klutuk plant (Musa balbisiana Colla). The identification results showed that the samples used were true klutuk banana plants (Musa balbisiana Colla).

The crude drug of the klutuk banana peel powder was extracted using the reflux method. The reflux process using 96\% ethanol solvent with $100 \mathrm{~g}$ of crude drug was carried out 3 times. During the extraction process, sample will be experienced by breaking down of cell walls and membranes due to heating [17]. The liquid extract was thickened applying a rotary evaporator and a water bath at temperature of $70^{\circ} \mathrm{C}$ in order to evaporate the solvent until a thick extract was obtained. The yield of the extract can be seen in table 1 .

Table 1: Density of extract and fractions

\begin{tabular}{lll}
\hline Sample & Yield (\%) & Density 1\% extract (g/ml) \\
\hline Ethanol peel extract & 8.18 & 0.83 \\
N-hexane peel Fraction & 3.73 & 0.72 \\
Ethyl acetate peel fraction & 4.08 & 0.84 \\
Water peel fraction & 9.19 & 0.94 \\
\hline
\end{tabular}

Fractionation was carried out from the ethanol extract of klutuk banana peels based on differences solvent polarity, namely ethyl acetate, $\mathrm{n}$-hexane, and water. The $\mathrm{n}$-hexane solvent is non-polar, ethyl acetate is semi-polar, and water is polar. The yield and density of extract and fractions were shown on table 1.

The yield of the water fraction is greater than the n-hexane and ethyl acetate fractions. The water is a polar solvent which has the ability to attract polar compounds. From this result, it could be concluded that the peels of klutuk banana contained more polar compounds. Meanwhile, research by Kusumah which used maceration method using $70 \%$ ethanol solvent, the yields extracts were: klutuk banana peel $9.28 \%$ and kepok banana peel $6.48 \%$, respectively [18].

The determination of density of the extract and fractions is one of the non-specific parameters. The aim of the determination of density was to provide an overview of the dissolved chemical content in an extract and fractions [11], and density among the sample should be similar, therefore the effect between one sample and the other sample can be compared. The results of the determination of density were presented on the table 1.

Table 2: Phytochemical screening of crude drug, extract and fractions of klutuk banana peel

\begin{tabular}{lllll}
\hline Groups & $\begin{array}{l}\text { Crude } \\
\text { drug }\end{array}$ & $\begin{array}{l}\text { Ethanol } \\
\text { extract }\end{array}$ & $\begin{array}{l}\text { N-hexane } \\
\text { fraction }\end{array}$ & $\begin{array}{l}\text { Ethyl acetate fraction } \\
\text { fraction }\end{array}$ \\
\hline Alkaloid & - & - & - & - \\
Flavonoid & + & + & - & + \\
Polyphenol & + & + & - & + \\
Tannin & + & - & - & - \\
Saponin & + & + & - & + \\
Monoterpenoid and sesquiterpenoid & + & + & + \\
Steroid/Triterpenoid & + & + & + \\
Quinone & + & + & + \\
\hline
\end{tabular}

Note: $(+)$ : detected, (-): not detected

The crude drug and ethanol extract of the klutuk banana peel contained flavonoid, polyphenol, monoterpenoid and sesquiterpenoid, saponin, quinone, steroid/triterpenoid, which were expressed on table 2 . The results were similar to the literature, which mentioned that the phytochemical content in klutuk banana peel contained of flavonoids, tannins, saponin, monoterpenoids and sesquiterpenoids [18]. The ethanol solvent which is used for extraction has a polarity index of 5.2; therefore, various compounds, both polar and nonpolar which contained in klutuk banana peels could be attracted [19]. The tannin was not detected in the extract due to hydrolysis reaction during the extraction and heating process [20]. The n-hexane fraction contained steroid/triterpenoid, monoterpenoid and sesquiterpenoid compounds due to the nonpolar properties of these compounds that easily dissolved in nonpolar solvents such as n-hexane [21]. The ethyl acetate fraction showed positive results for the flavonoid, polyphenol, quinone, steroid/triterpenoid, monoterpenoid and sesquiterpenoid compounds. The semi-polar ethyl acetate solvent could attract polar 
compounds such as flavonoids, polyphenols, and quinones, presumably because the resonating electrons in the benzene ring reduce the polarity of these compounds so that they are more attracted to ethyl acetate solvents [22]. Furthermore, the steroid/triterpenoid, monoterpenoid and sesquiterpenoid compounds are non-polar but still attracted to the ethyl acetate solvent, presumably because of the hydrogen bonding between the terpenoids, which have a hydroxyl group [23]. The water fraction showed positive results for flavonoids, polyphenols, and saponins. The flavonoid and saponin could be attracted because flavonoids could bind to sugar as glycosides, in a while saponin provided polar properties $[23,24]$. The alkaloid test showed negative results in all samples, which means that klutuk banana peel did not contain alkaloid compounds.

\section{Antioxidant activity}

The determination of the maximum wavelength is carried out to determine the highest absorption wavelength. The determination of the maximum wavelength of DPPH solution with a concentration of $30 \mu \mathrm{g} / \mathrm{ml}$ in methanol using a UV-visible spectrophotometer was at range $400 \mathrm{~nm}-800 \mathrm{~nm}$. The results showed that the maximum absorption wavelength for DPPH was $516 \mathrm{~nm}$. This DPPH maximum wavelength provided the maximum absorption of the test solution and the greatest sensitivity [25].

The vitamin $\mathrm{C}$ was used as a comparison because it functions as a secondary antioxidant, which demonstrated free radicals activity and prevent chain reactions [26]. The ratio of 1: 1 mixing was carried out for DPPH $30 \mu \mathrm{g} / \mathrm{ml}$ with extract, n-hexane, ethyl acetate, water fractions and vitamin $C$ into each concentration as much as 1 $\mathrm{ml}$. Subsequently, the solution was incubated for $30 \mathrm{~min}$ at room temperature. Then the absorbance measurement was carried out using UV-visible spectrophotometry at a wavelength of $516 \mathrm{~nm}$ and replicated three times so that the results obtained were more accurate. The decrease in the absorbance of DPPH at a wavelength of $516 \mathrm{~nm}$ indicated that the compound has antioxidant activity. The higher reducing in DPPH absorbance will be demonstrated by higher concentration of the fraction [27].

The results presented a change in color intensity marked by decreasing in DPPH absorbance due to the addition of sample. The change in purple color intensity is due to the DPPH radical scavenging activity which is produced by reaction between DPPH molecule and hydrogen atom that released by sample to form a diphenyl picryl hydrazine compound [27].

Based on the absorbance value obtained then be calculated the percentage of DPPH radical scavenging activity. The $\mathrm{IC}_{50}$ value can be investigated from the linear regression equation. The $\mathrm{IC}_{50}$ was sample concentration that can scavenge DPPH activity as much as $50 \%$. The smaller $\mathrm{IC}_{50}$ value is the higher antioxidant activity [28]. The sample provided very strong antioxidant if the $\mathrm{IC}_{50}$ value is $<50$ $\mu \mathrm{g} / \mathrm{ml}$, strong if the $\mathrm{IC}_{50}$ value is $50-100 \mu \mathrm{g} / \mathrm{ml}$, moderate if the $\mathrm{IC}_{50}$ value is $100-150 \mu \mathrm{g} / \mathrm{ml}$, and weak if the $\mathrm{IC}_{50}$ value is $151-200 \mu \mathrm{g} / \mathrm{ml}$, and inactive if it has an $\mathrm{IC}_{50}$ value $>200 \mu \mathrm{g} / \mathrm{ml}$ [29].

The determination of Antioxidant Activity Index (AAI) value was very important to classify the antioxidant properties of the test sample. The AAI value is a value that indicated the antioxidant activity of test sample. This AAI value could be determined by dividing the final DPPH concentration used $(\mu \mathrm{g} / \mathrm{ml})$ with the $\mathrm{IC}_{50}$ value $(\mu \mathrm{g} / \mathrm{ml})$ obtained from each test sample. The antioxidant were weak if value of $\mathrm{AAI}<0.5$, moderate if AAI $>0.5-1$, strong if $\mathrm{AAI}>1-2$, and very strong if AAI $>2$ [30].

The results presented that the n-hexane, ethanol extract, ethyl acetate, water fractions of klutuk banana (Musa balbisiana Colla) peels and vitamin $\mathrm{C}$ had the ability to scavenge DPPH free radicals. The results of antioxidant activity of extract and fractions of klutuk banana peel were expressed on the table 3 .

Table 3: Antioxidant activity of extracts and fractions

\begin{tabular}{lll}
\hline Sample & $\mathbf{I C}_{50}(\boldsymbol{\mu g} \mathbf{g} \mathbf{m l})$ & AAI \\
\hline Ethanol peel extract & 1.92 & 7.80 \\
N-hexane peel fraction & 3.65 & 4.10 \\
Ethyl acetate peel fraction & 0.37 & 40.45 \\
Water peel fraction & 5.77 & 2.60 \\
Vitamin C & 0.17 & 83.80 \\
\hline
\end{tabular}

The $\mathrm{IC}_{50}$ value of the ethanol extract, n-hexane, ethyl acetate and water fractions were $1.92 \mu \mathrm{g} / \mathrm{ml}, 3.65 \mu \mathrm{g} / \mathrm{ml}, 0.37 \mu \mathrm{g} / \mathrm{ml}$, and 5.77 $\mu \mathrm{g} / \mathrm{ml}$, respectively. Furthermore, this study showed that $\mathrm{IC}_{50}$ of DPPH of ethyl acetate peels extract of ambon lumut banana had the highest ABTS scavenging capacity with $\mathrm{IC}_{50} 1.91 \mu \mathrm{g} / \mathrm{ml}$ and ethanolic extract of muli banana had the highest DPPH scavenging activities with $\mathrm{EC}_{50} 4.39 \mu \mathrm{g} / \mathrm{ml}$, respectively [31]. Based on these results, the n-hexane, ethyl acetate, and water fractions of the banana peel demonstrated very strong antioxidant activity $(<50 \mu \mathrm{g} / \mathrm{ml})$ [32]. Furthermore the results of the AAI for the ethanol extract, n-hexane, ethyl acetate and water fractions were 7.80, 4.10, 40.45, and 2.60, respectively. In a while, the antioxidant activity of vitamin $C$ result was revealed $\mathrm{IC}_{50}$ value $0.1790 \mu \mathrm{g} / \mathrm{ml}$ and AAI value 83.80 which showed very strong antioxidant category [33].

The concentration is directly proportional to the percentage of DPPH scavenging activity, higher concentration will give higher percentage of scavenging activity. The highest to the lowest yields of the antioxidant activity were ethyl acetate fraction>ethanol extract $>n-$ hexane fraction>water fraction. It could be be seen from the results of phytochemical screening that the extract contained flavonoid, polyphenol, monoterpenoid and sesquiterpenoid, saponin, steroid/triterpenoid, and quinone; the n-hexane fraction contained monoterpenoid and sesquiterpenoid; ethyl acetate fraction contained flavonoid, polyphenol, quinone; and water fraction contain flavonoid, polyphenol and saponin. Flavonoid and polyphenol compounds have antioxidant activity by donating hydrogen ions so that they can stabilize reactive free radicals and act as direct free radical scavengers [34]. The terpenoid class compounds work as antioxidants by donating hydrogen atoms to inhibit lipid peroxidation (LPO) [35]. Saponin has an antioxidant and capable of reducing superoxide through the formation of hydroperoxide intermediates to prevent free radical biomolecular damage [36].

\section{Antihyperglycemic activity}

Antihyperglycemic activity was carried out by the oral glucose tolerance test method as a preliminary test to determine the ability of the ethyl acetate, n-hexane and water fractions of the peel of klutuk banana in reducing blood glucose levels in normal male mice after being induced with glucose monohydrate $2 \mathrm{~g} / \mathrm{kg}$ bw solution.

The results of antihyperglycemic effect of fractions of klutuk banana (M. balbisiana Colla) were presented in fig. 1. The percentage of blood glucose level reduction was demonstrated in table 1 . The profile of blood glucose levels (fig. 1) showed that at $30 \mathrm{~min}$ there was an enlarge in blood glucose levels in each test group due to the glucose absorption process given. Based on experimental data at $60 \mathrm{~min}$, it was known that giving klutuk banana peel fractions had ability to inhibit the increasing in glucose levels. The mean blood glucose levels for the initial conditions of all the test materials were lower and significantly different $(p<0.01)$ compared to the negative control group. 


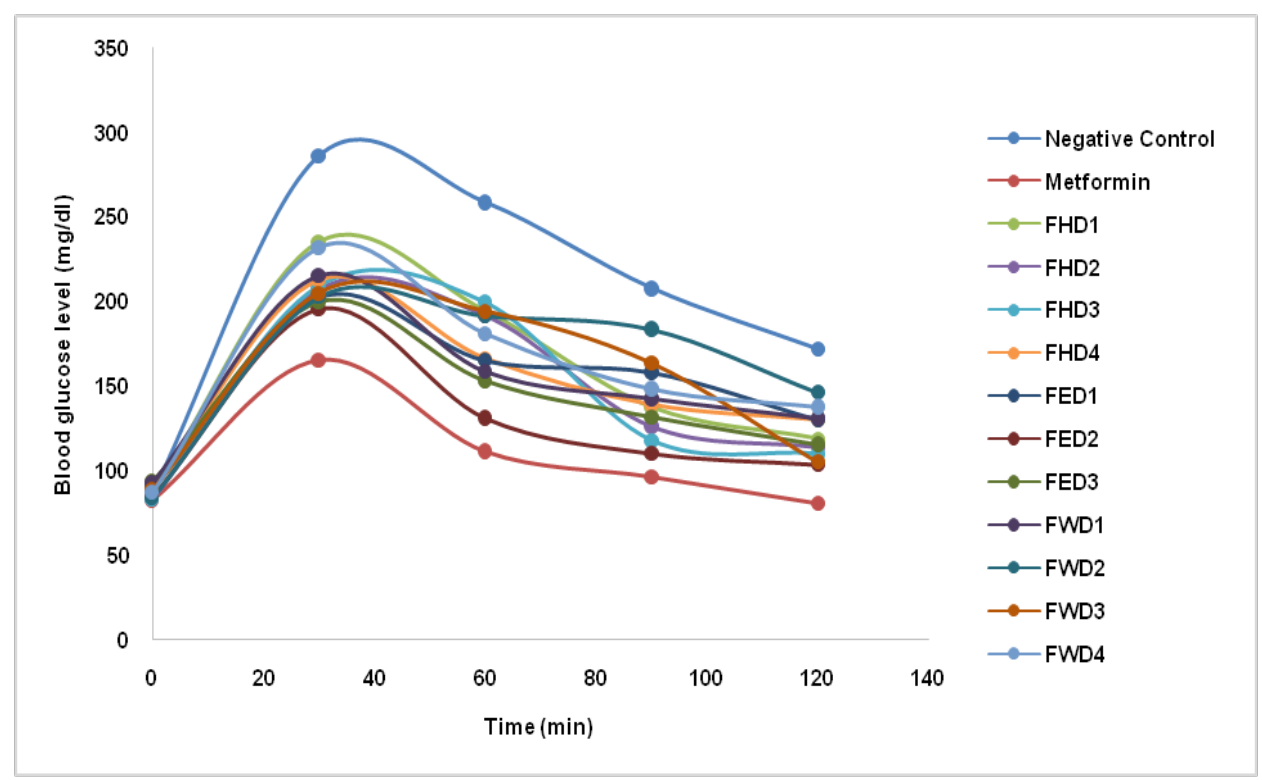

Fig. 1: Antihyperglycemic effect of klutuk banana peel fractions, Negative control; CMC-Na 0.5\%; positive control; metformin $65 \mathrm{mg} / \mathrm{kg}$ bw; FHD1; n-hexane klutuk peel fraction $6.5 \mathrm{mg} / \mathrm{kg} \mathrm{bw}$, FHD2; $13 \mathrm{mg} / \mathrm{kg} \mathrm{bw}$, FHD3; $14.5 \mathrm{mg} / \mathrm{kg} \mathrm{bw}$, FHD4; $26 \mathrm{mg} / \mathrm{kg} \mathrm{bw,} \mathrm{FED1} \mathrm{(ethyl}$ acetate klutuk peel fraction $7.25 \mathrm{mg} / \mathrm{kg} \mathrm{bw}$ ), FED2 (14.5 mg/kg bw), FED3 (29 mg/kg bw), FWD1 (water klutuk peel fraction 14,5 mg/kg bw), FWD2 (16 mg/kg bw), FWD3 (32 mg/kg bw), and FWD4 (64 mg/kg bw)

Antihyperglycemic effect of banana may be due to the presence of phytoconstituents such as tannin, saponin and flavonoid [8]. Phytochemical investigation of different fractions of klutuk banana peel has demonstrated the attendance of flavonoid and tannin (e. g. gallocatechin) [37, 38]. These materials are commonly implicated for its antihyperglycemic effects $[39,40]$. The banana peels are also high in phytochemical compounds, mostly antioxidants. Anthocyanins, cyanidine, delphinidin, and catecholamine can all contribute to banana peeling antihyperglycemic activity [39]. One of the reasons for the antihyperglycemic effect may be the suppression of intestinal glucose absorption or enhanced insulin secretion by pancreatic beta cells. Gallocatechin is one of the active compound of banana peel that facilitates the use of peripheral glucose $[35,40]$.

The percentage of blood glucose levels reduction in 120 min compared to $30 \mathrm{~min}$ can bee seen in table 4 . Based on table 4 it can be told that the reduction in blood glucose levels in each group of klutuk banana peel fractions at $120 \mathrm{~min}$ compared to glucose levels at $30 \mathrm{~min}$ were as follows:Metformin $>$ FED2 $>$ FHD1 $>$ FED3 $>$ FWD1 $>$ FWD4 $>$ FHD3 $>$ FHD4 $>$ FHD2 $>$ FED1 $>$ FWD3 $>$ FWD2.

Table 4: Percentage of blood glucose levels reduction in $120 \mathrm{~min}$ compared to $30 \mathrm{~min}$

\begin{tabular}{llll}
\hline Groups & $\begin{array}{l}\text { Average 30 } \mathbf{m i n} \text { blood glucose } \\
\text { level (mg/dl) }\end{array}$ & $\begin{array}{l}\text { Average 120 min blood glucose } \\
\text { level (mg/dl) }\end{array}$ & Blood glucose reduction (\%) \\
\hline Metformin & $165 \pm 7.00^{* *}$ & $113 \pm 7.68^{* *}$ & 31.50 \\
FHD1 & $235 \pm 6.51^{* *}$ & $172 \pm 5.51^{* *}$ & 27.05 \\
FHD2 & $207 \pm 6.16^{* *}$ & $160 \pm 9.41^{* *}$ & 22.83 \\
FHD3 & $209 \pm 11.50^{* *}$ & $159 \pm 10.54^{* *}$ & 23.93 \\
FHD4 & $13 \pm 7.51^{* *}$ & $162 \pm 2.84^{* *}$ & 23.82 \\
FED1 & $164 \pm 10.25^{* *}$ & 19.00 \\
FED2 & $135 \pm 10.31^{* *}$ & 31.01 \\
FED3 & $193 \pm 13.32^{* *}$ & $150 \pm 10.67^{* *}$ & 24.92 \\
FWD1 & $196 \pm 14.29^{* *}$ & $162 \pm 8.53^{* *}$ & 24.77 \\
FWD2 & $200 \pm 8.96^{* *}$ & $181 \pm 6.52^{* *}$ & 10.65 \\
FWD3 & $216 \pm 11.59^{* *}$ & $167 \pm 6.43^{* *}$ & 18.50 \\
FWD4 & $203 \pm 11.24^{* *}$ & $175 \pm 9.09^{* *}$ & 24.57 \\
\hline
\end{tabular}

Data are expressed as mean \pm SEM, $n=3$ animals per group. One-way ANOVA post-test Tukey, ${ }^{* *} \mathrm{p}<0.01$ compared to negative control

Based on the results that have been carried out in the research as shown in fig. 2 could be explained that the percentage reduction in blood glucose levels of the klutuk banana peel fraction compared to the negative control. The best result was given by the ethyl acetate fraction group with a dose of 14.5 $\mathrm{mg} / \mathrm{kg}$ bw (FED2) with a decrease in percentage at $30 \mathrm{~min}(-$ $32 \%$; p.0.000), $60 \min (-49 \%$; p. 0.000), $90 \min (-47 \%$; p. 0.000$)$ and $120 \mathrm{~min}(40 \%$; p. 0.000$)$. This result similar to research by Navghare VV and Dhawale SC which provided anti- hyperglycemic impact of Musa sapientum ethanol extract (EMS), Musa cavendish (EMC), M. paradisiaca (EMP), and M. acuminata (EMA) peels by Normoglycemic (having natural glucose concentration) oral glucose tolerance test in glucose-loaded $(2$ g/kg p. o.). This previous study revealed that EMC (500 and 1000 $\mathrm{mg} / \mathrm{kg}$, p. o.) and EMA (200 and $400 \mathrm{mg} / \mathrm{kg} \mathrm{p.} \mathrm{o.)} \mathrm{presented} \mathrm{anti-}$ hyperglycemic effect $(\mathrm{p}<0.01)$. Meanwhile, both EMS $(200$ $\mathrm{mg} / \mathrm{kg}$, p. o.) and EMP $(500 \mathrm{mg} / \mathrm{kg}$, p. o.) also represented significant decrease $(\mathrm{p}<0.01)$ in blood glucose level [8]. 


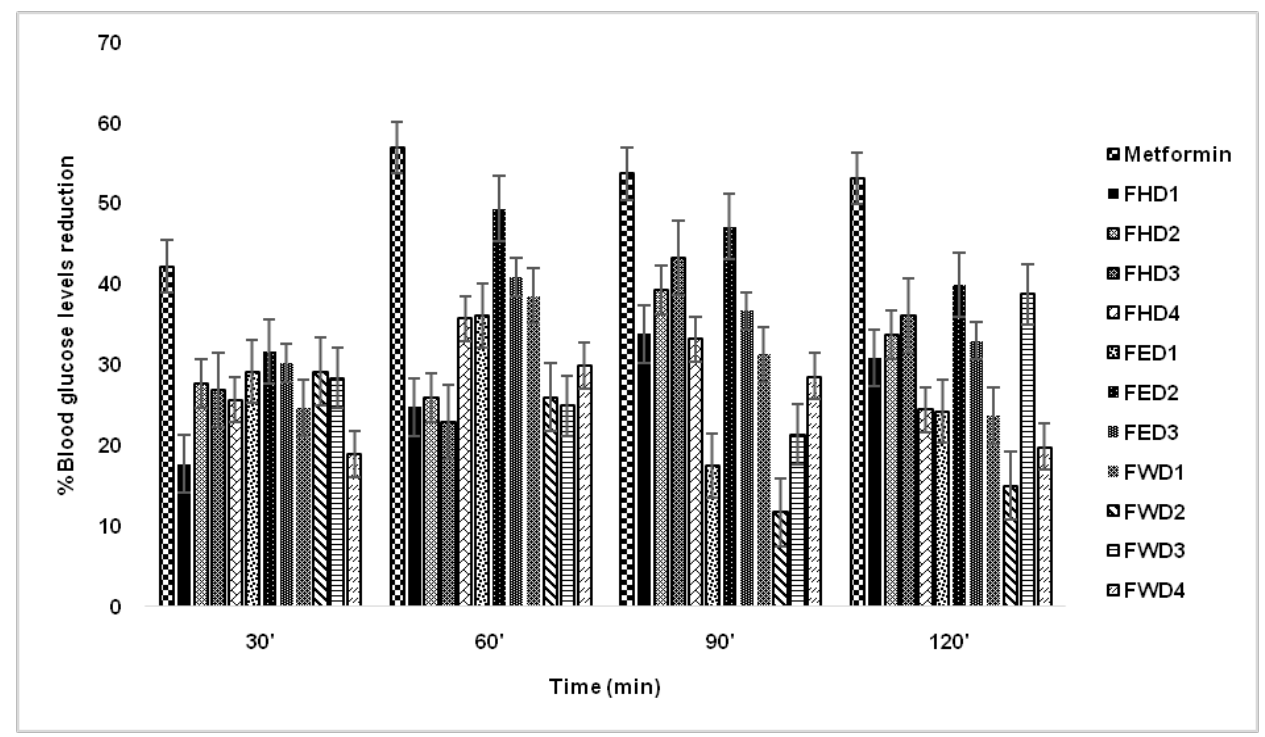

Fig. 2: The percentage reduction of blood glucose levels after treatment by different fractions peels of $M$. balbisiana Colla Negative control; CMC-Na 0.5\%; positive control; metformin $65 \mathrm{mg} / \mathrm{kg}$ bw; FHD1; n-hexane klutuk peel fraction $6.5 \mathrm{mg} / \mathrm{kg} \mathrm{bw,} \mathrm{FHD2;} 13 \mathrm{mg} / \mathrm{kg} \mathrm{bw}$, FHD3; $14.5 \mathrm{mg} / \mathrm{kg}$ bw, FHD4; $26 \mathrm{mg} / \mathrm{kg}$ bw, FED1 (ethyl acetate klutuk peel fraction $7.25 \mathrm{mg} / \mathrm{kg} \mathrm{bw}$ ), FED2 (14.5 mg/kg bw), FED3 (29 $\mathrm{mg} / \mathrm{kg} \mathrm{bw}$ ), FWD1 (water klutuk peel fraction 14,5 mg/kg bw), FWD2 (16 mg/kg bw), FWD3 (32 mg/kg bw), and FWD4 (64 mg/kg bw). Data are expressed as mean \pm SEM $n=3$ animals per group. One-way ANOVA post-test Tukey, ${ }^{* *} \mathbf{p}<0.01$ compared to negative control

The results of other studies that have been done it can be explained that the reduction in blood glucose levels was suspected by repairing the pancreatic $\beta$ cells which produce insulin, due to banana peel fractions contained secondary metabolites, namely flavonoids. In general, there is very little biological knowledge of particular diabetes treatment modes of action, although most plants have been observed to contain substances such as alkaloids, glycosides, flavonoids and terpenoids, which are often involved in anti-diabetic impact.

The previous study stated that flavonoids had antioxidant activity that protect the body from the damage triggered by species of reactive oxygen, Flavanols are found abundantly in bananas [41]. In addition, flavonoids themselves are able to regenerate pancreatic $\beta$ cells so that insulin deficiency can be overcome [42]. Flavonoids are also thought to reduce blood glucose levels by inhibiting the absorption of glucose from the lumen of the gastrointestinal tract, especially flavonoid glycosides [43]. By inhibiting glucose digestion and transport in the small intestine, by raising glucose storage in tissues, and by preserving and regenerating damaged $\beta$-cells, and/or improving the secretion of pancreatic insulin, flavonoids may decrease postprandial blood glucose [44]. In comparison, banana peel phenolic content was higher relative to other fruits such as papaya, pineapple, avocado, melon, passion fruit and watermelon [45]. Therefore, banana is perhaps the perfect diabetes management nominee [46].

\section{CONCLUSION}

Fractions of klutuk banana (Musa balbisiana Colla) peel had antioxidant and antihyperglycemic activity. Klutuk banana fractions were categorized as very strong antioxidant. The highest antioxidant activity was exposed by ethyl acetate fraction and the best antihyperglycemic activity was presented by ethyl acetate fraction with dose of $14.5 \mathrm{mg} / \mathrm{kg}$ bw.

\section{ACKNOWLEDGEMENT}

The author gratefully thankful for financial support from Ristek DIKTI Indonesia (PDD). The grant No: 1827/UN6.3.1/lT/2020.

\section{FUNDING}

The funding from Ministry of Research, Technology and Higher Education, Republic of Indonesia.

\section{AUTHORS CONTRIBUTIONS}

All the authors have contributed equally.

\section{CONFLICT OF INTERESTS}

Authors declare no conflict of interest.

\section{REFERENCES}

1. American Diabetes Association. Classification and diagnosis of diabetes: standards of medical care in diabetes-2020. Diabetes Care 2020;43:14-31.

2. Bharti SK, Krishnan S, Kumar A, Kumar A. Antidiabetic phytoconstituents and their mode of action on metabolic pathways. Ther Adv Endocrinol Metab 2018;9:81-100.

3. Krinsky NI, Johnson EJ. Carotenoid actions and their relation to health and disease. Mol Aspects Med 2005;26:459-516.

4. Wall MM. Ascorbic acid, vitamin a, and mineral composition of banana (Musa sp.) and papaya (Carica papaya) cultivars grown in Hawaii. J Food Compos Anal 2006;19:434-45.

5. Singh B, Singh JP, Kaur A, Singh N. Bioactive compounds in banana and their associated health benefits-a review. Food Chem 2016;206:1-11.

6. Vijayakumar S, Presannakumar G, Vijayalakshmi NR. Antioxidant activity of banana flavonoids. Fitoterapia 2008;79:279-82.

7. Singh A, Singh S. Dietary fiber content of Indian diets. Asian J Pharm Clin Res 2015;8:58-61.

8. Navghare VV, Dhawale SC. In vitro antioxidant, hypoglycemic and oral glucose tolerance test of banana peels. Alexandria J Med 2017;53:237-43.

9. Nofianti T, Muhtadi A, Fidrianny I. Comparison of hypoglicemic effect of extract rinds, flesh, seeds and flowers Musa balbisiana colla in a mice. Abstract Proceeding 2nd Postgraduate Seminar on Pharmaceutical Sciences; 2019.

10. Meliala A, Sumiwi YAA, Narwidina P, Rini SLS, Setyaningsih W. Banana peel flakes alleviate blood glucose and stress in a dosedependent manner. Int J Pharm Pharm Sci 2020;12:75-81.

11. Ministry of Health of the Republic of Indonesia. General Standard Parameters of Medicinal Plant Extracts. Jakarta: Directorate General of Food and Drug Control; 2000.

12. Borah M, Das S. Antidiabetic, antihyperlipidemic, and antioxidant activities of Musa balbisiana Colla. in type 1 diabetic rats. Indian J Pharmacol 2017;49:71-6.

13. Malpani MO, Rajput PR, Chinchole KV, Kapse SS, Ambarkar KS. Phytochemical screening and antioxidant activity of extracts of Xanthium strumarium, chrysanthemum and their mixture. Rasayan J Chem 2019;12:1901-8. 
14. Ighodaro OM, Adeosun AM, Asejeje FO, Soetan GO, Kassim OO Time course effects of 5,5-dihydroxylpyrimidine-2,4,6-trione (alloxan) as a diabetogenic agent in animal model. Alexandria Med J 2018;54:705-10.

15. Tchimene MK, Okoli CO, Iwu MM. Antidiabetic property of some Nigerian medicinal plants. J Med Plants Res 2016;10:139-48.

16. Oskouei BG, Ravasjani SA, Musavinejad SJ, Salehzadeh SA, Abdolhosseinzadeh A, Hamishehkar $\mathrm{H}$, et al. In vivo evaluation of anti-hyperglycemic, anti-hyperlipidemic and anti-oxidant status of liver and kidney of thymol in STZ-induced diabetic rats. Drug Res (Stuttg) 2019;69:46-52.

17. Anal AK, Jaisanti S, Noomhorm A. Enhanced yield of phenolic extracts from banana peels (Musa acuminata Colla AAA) and cinnamon barks (Cinnamomum varum) and their antioxidative potentials in fish oil. J Food Sci Technol 2014;51:2632-9.

18. Kusuma SAF, Pebrianti M, Saraswati A. Comparison of unripe banana peel of kapok (Musa paradisiaca L.) and klutuk (Musa balbisiana Colla): phytochemical and anti-dysenteriae activity. J Pharm Sci Res 2018;10:911-4.

19. Toh PY, Leong FS, Chang SK, Khoo HE, Yim HS. Optimization of extraction parameters on the antioxidant properties of banana waste. Acta Sci Pol Technol Aliment 2016;15:65-78.

20. Martinez PDH, Merle J, Labidi J, Bouhtoury FCE. Tannins extraction: a key point for their valorization and cleaner production. J Clean Prod 2019;206:1138-55.

21. Mustarichie R, Runadi D, Ramdhani D. The antioxidant activity and phytochemical screening of ethanol extract, fractions of water, ethyl acetate, and n-hexane from mistletoe tea (Scurrula atropurpurea. BL. Dans). Asian J Pharm Clin Res 2017;10:343-7.

22. Thavamoney N, Sivanadian L, Tee LH, Khoo HE, Prasad KN, Kong KW. Extraction and recovery of phytochemical components and antioxidative properties in fruit parts of Dacryodes rostrata influenced by different solvents. J Food Sci Technol 2018;55:2523-32.

23. Jiang Z, Kempinski C, Chappell J. Extraction and analysis of terpenes/terpenoids. Curr Protoc Plant Biol 2016;1:345-58.

24. Gonzalez MLC, Sepulveda L, Verma DK, Garcia HAL, Duran LVR, Llina $\mathrm{A}$, et al. Review conventional and emerging extraction processes of flavonoids. Processes 2020;8:1-29.

25. Nerdy N, Manurung K. Spectrophotometric method for antioxidant activity test and total phenolic determination of red dragon fruit leaves and white dragon fruit leaves. Rasayan J Chem 2018;11:1183-92.

26. Sanchez NFS, Coronado RS, Canongo CV, Carlos BH. Chapter antioxidant compounds and their antioxidant mechanism. Intech Open 2019;1-28. DOI:10.5772/intechopen.85270

27. Zahoor M, Zafar R, Rahman NU. Isolation and identification of phenolic antioxidants from Pistacia integerrima gall and their anticholinesterase activities. Heliyon 2018;4:1-22.

28. Jan S, Khan MR, Rashid U, Bokhari J. Assessment of antioxidant potential, total phenolics and flavonoids of different solvent fractions of Monotheca buxifolia fruit. Osong Public Health Res Perspect 2013;4:246-54.

29. Marjoni MR, Zulfisa A. Antioxidant activity of methanol extract/fractions of senggani leaves (Melastoma candidum D. Don). Pharm Anal Acta 2017;8:8:1-6.
30. Vargas RA, Zamilpa A, Petricevich VL. Development and validation of conditions for extracting flavonoids content and evaluation of antioxidant and cytoprotective activities from Bougainvillea x buttiana Bracteas (var. Rose). Antioxidants 2019;8:1-16.

31. Fidrianny I, Rizki K, Insanu M. In vitro antioxidant activities from various extracts of banana peels using ABTS, DPPH assays and correlation with phenolic, flavonoid, carotenoid content. Int J Pharm Pharm Sci 2014;6:299-303.

32. Setiawan NCE, Amalia H. Antioxidant activity of Areca vestiaria Giseke fruit seed extract and its fractions using the DPPH method (2,2-diphenyl-1-picrylhydrazyl). J Cis-Trans (JC-T) 2017;1:9-13.

33. Handayani V, Ahmad AR, Sudir M. Antioxidant activity test of flower methanol extract and patikala leaf (Etlingera elatior (Jack) R. M. Sm) using the DPPH method. Pharm Sci Res 2014;1:86-93.

34. Lobo V, Patil A, Phatak A, Chandra N. Free radicals, antioxidants and functional foods: impact on human health. Pharmacogn Rev 2010;4:118-26.

35. Félix R, Valentão P, Andrade PB, Felix C, Novais SC, Lemos MFL. Review evaluating the in vitro potential of natural extracts to protect lipids from oxidative damage. Antioxidants 2020;9:1-29.

36. Navghare VV, Dhawale SC, Phanse MA, Ingole PG, Pawale SS, Sonwane PP. Free radical scavenging property of some commonly known Musa species. Indo Am J Pharm Res 2013:3:6027-34.

37. Matsudha H, Morikawa T, Yoshikawa M. Antidiabetogenic constituents from several natural medicine. Pure Appl Chem 2002;74:1301-8.

38. Guy K, Jaekyung K, Klaus H, Yanyan C, Xiaozhuo C. Antidiabetes and anti-obesity activity of Laserstroemia speciose. Evid Complement Alternat Med 2007;44:401-7.

39. Pereira A, Maraschin M. Banana (Musa spp.) from peel to pulp: ethnopharmacology, source of bioactive compounds and its relevance for human health. J Ethnopharmacol 2015; 160:149-63.

40. Anderson RA, Polansky MM. Tea enhances insulin activity. J Agric Food Chem 2002;50:7182-6.

41. Panche AN, Diwan AD, Chandra SR. Review article flavonoids: an overview. J Nutr Sci 2016;5:47, 1-15.

42. Saritha M. Flavonoids-the most potent poly-phenols as antidiabetic agents: an overview. Mod Appro Drug Des 2017;24:1-5.

43. Susilawati E. Antidiabetic activity of ethanol extract of hanjeli seed (Coix lacryma-Jobi) in alloxan-induced swiss webster mice. J Farm Galen 2017;2:77-82

44. Alkhalidy $\mathrm{H}$, Wang $\mathrm{Y}$, Liu D. Dietary flavonoids in the prevention of T2D: an overview. Nutrients 2018;10:1-33.

45. Kondo S, Kittikorn M, Kanlayanarat S. Preharvest antioxidant activities of tropical fruit and the effect of low temperature storage on antioxidants and jasmonates. Postharvest Biol Technol 2005;36:309-18.

46. Ahmad BA, Zakariyya UA, Abubakar M, Sani MM, Ahmad MA Chapter pharmacological activities of banana. Intech Open 2019;1-20. DOI:10.5772/intechopen.83299 